\title{
Nutrition amid the COVID-19 pandemic: a multi-level framework for action
}

\author{
Farah Naja ${ }^{1} \cdot$ Rena Hamadeh ${ }^{1}$
}

Received: 24 March 2020 / Revised: 1 April 2020 / Accepted: 1 April 2020 / Published online: 20 April 2020

(c) Springer Nature Limited 2020

COVID-19, a disease caused by a novel coronavirus, became a major global human threat that has turned into a pandemic. Coronavirus is one of the major pathogens that mainly targets the human respiratory system. In late December 2019, a cluster of patients were admitted to hospitals with an initial diagnosis of pneumonia of an unknown etiology [1]. Early reports predicted the onset of a possible coronavirus outbreak called SARS-CoV-2, causing the disease COVID-19. The ongoing epidemic has been declared by the World Health Organization (WHO) as a global public health emergency [2].

Experiences from previous outbreaks have shown that as an epidemic evolves, there is an urgent need to expand public health activities beyond direct clinical management and extend to cover basic principles of management and optimization of resource utilization [3]. Since the outbreak of the COVID-19, individual and community resilience emerged as a main resource while remaining the first line of defense in emergency preparedness. In fact, psychological and behavioral countermeasures of both the individual and the community are vital determinants to improve resilience and enhance the efficacy of public health approaches vis a vis a pandemic of a magnitude similar to that of COVID-19 [4]. The nutritional status of individuals has for long been considered as an indicator of resilience against destabilization [5]. The ecology of adversity and resilience demonstrates that substantial stressors, such as inadequate nutrition, can lead to long-lasting effects that are linked to health [6]. In fact, poor diet quality has been associated not only with physical but also mental health [7]. Optimal nutrition and dietary intake is a resource that transcends the individual, the community to reach global influence [8].

Farah Naja

fn14@aub.edu.lb

1 Department of Nutrition and Food Sciences, American University of Beirut, Beirut, Lebanon
In order to enhance the physical and mental health of individuals vis a vis the COVID-19 pandemic, this commentary presents a framework for action to maintain optimal nutrition at the individual, community, national and global levels using an adapted version of the ecological model of health behavior (Fig. 1).

At the individual level, the common denominator that drives most of the nutrition and dietary recommendations to combat viral infections, including COVID-19, lies within the link between diet and immunity. In fact, existing evidence highlights that diet has a profound effect on people's immune system and disease susceptibility. It has been demonstrated that specific nutrients or nutrient combinations may affect the immune system through the activation of cells, modification in the production of signaling molecules, and gene expression [9]. Furthermore, dietary ingredients are significant determinants of gut microbial composition and consequently can shape the characteristics of immune responses in the body [10]. Nutritional deficiencies of energy, protein, and specific micronutrients are associated with depressed immune function and increased susceptibility to infection. An adequate intake of iron, zinc, and vitamins $\mathrm{A}, \mathrm{E}, \mathrm{B} 6$, and B12 is predominantly vital for the maintenance of immune function [11]. Therefore, the key to maintaining an effective immune system is to avoid deficiencies of the nutrients that play an essential role in immune cell triggering, interaction, differentiation, or functional expression.

COVID-19 world pandemic imposed a new set of challenges for the individual to maintain a healthy diet. First, the state of lockdown announced in many countries around the globe led all public and private sector institutions, with the exception of health care facilities and a limited number of essential services, to close down and, if possible, carry its operations remotely (without face to face interactions). Individuals were asked to stay home and avoid contact with other people [12]. Such measures of self-isolation and social distancing are known to be crucial in limiting the spread of the virus, flattening the curve of incidence rate, and 
Fig. 1 A multi-level framework of action to support nutrition during the COVID-19 pandemic. A multilevel framework to support nutrition and food security during the COVID-19 pandemic, using the various levels of the ecological health model: individual, community, national and global.

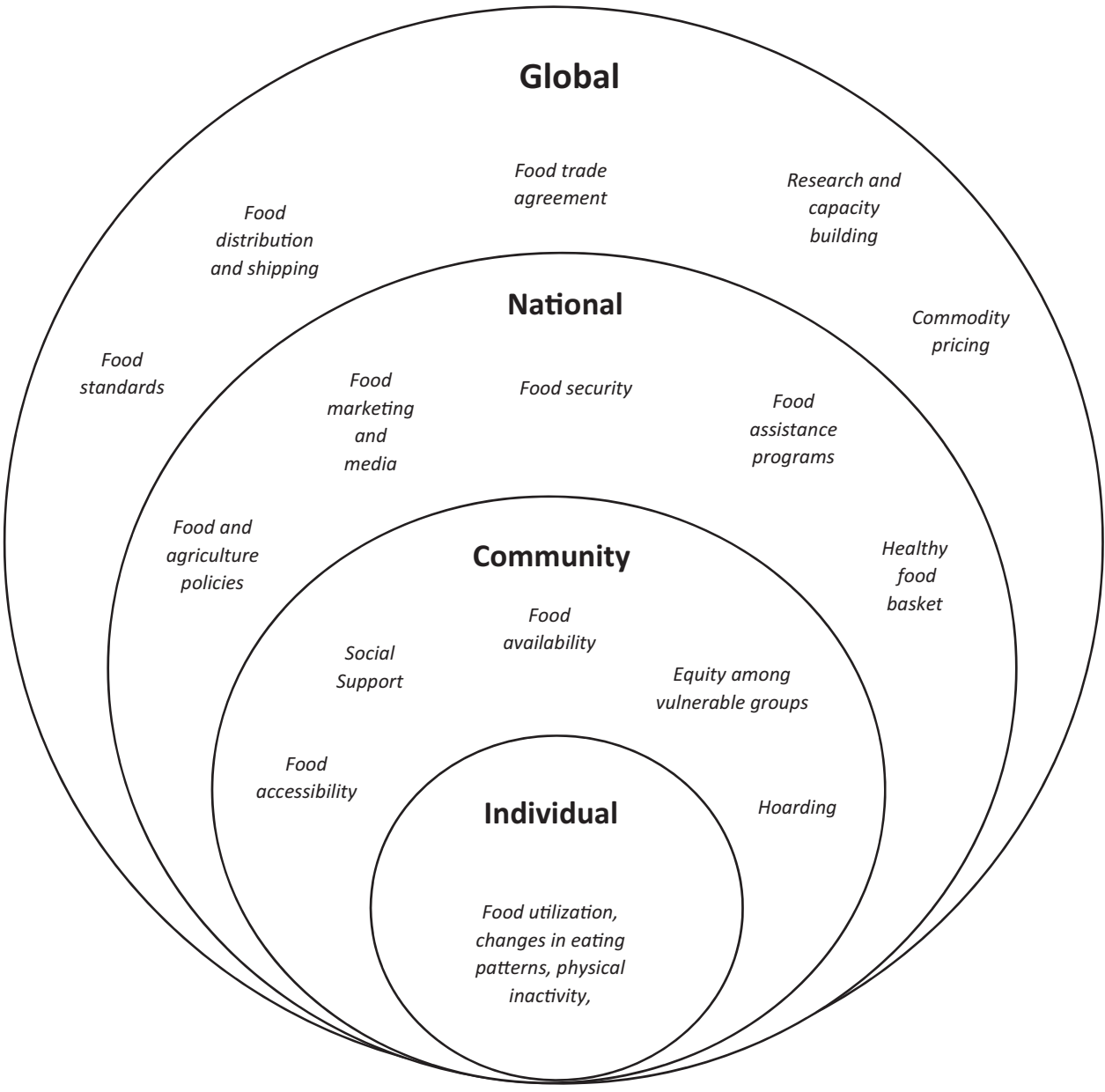

ultimately disease containment [13]. These measures have severe repercussions on both food access and utilization. Food access, however, is dependent on factors that could reach beyond the individual and are more directly related to actions and policies at the community, national as well as global levels. That said, the individual remains capable of making a few choices related to food utilization. The confinement to one's home has direct effects on one's lifestyle, including dietary habits, eating, and physical activity patterns. Confinement increases sedentary behaviors that involve activities with very low energy expenditure, performed mainly in a sitting or supine position [14]. The low physical activity levels, even for short periods, could negatively affect physical and mental health. The state of lockdown and confinement could also lead to irregular eating patterns and frequent snacking, both of which are associated with higher caloric intake and increased risk of obesity [15].

The changes in dietary patterns during the outbreak of COVID-19 could also be driven by the fear and anxiety many people around the globe are experiencing. Compelling evidence showed that dietary habits are affected by conditions of stress, distress, and emotional disturbance, whereby elevated distress levels are associated with unhealthy dietary patterns and poor quality of the diet [16]. Furthermore, emotions like fear and sadness are associated with less desire or motivation to eat and with lessened enjoyment during eating [17]. More recently, in explicating a five-way model of emotions and diet, it was found that changes in food intake may be the "natural" response to stress and heightened emotional states through both psychological and physiological mechanisms [18].

Therefore, the responsibility of the individuals during the COVID-19 pandemic lies in making an effort to choose a healthy lifestyle, eat diets high in fruits and vegetables, exercise during free time, try to maintain a healthy weight, and get an adequate amount of sleep. In addition to taking care of one's dietary intake, the collective responsibility of individuals is to avoid the spread of misinformation related to nutrition and dietary intake, and the COVID-19. Since the outbreak, networks of social media were flooded by messages of single foods/herbs promising cure or prevention of the infection. The effects of such unfounded claims could lead to negative implications ranging from giving a false sense of protection against the infection to toxicity. 
At the community level, food access and availability are particularly vulnerable to the implications of the COVID-19 outbreak, primarily because of difficulties in transportation, distribution, and delivery [19]. This situation has led in many instances to 'hoarding'. One way that a pandemic would indirectly impact the food supply chain is by changing consumer behavior. Pandemics create uncertainty and volatility in consumer demand, making it particularly challenging to maintain food inventories in a just in time economy [20]. In a study of the effect of an outbreak on behavior, the most recurrent response is to stockpile supplies, food, and water [21]. Those who can afford extra food may hoard more than they need and pose devastating consequences on at risk-populations. Hoarding could lead to extreme shortages in markets, leading to rapidly rising prices [22]. Therefore, at a community level, it is crucial to spread awareness against 'Panic-buy'. Furthermore, during the COVID-19 pandemic, older adults and patients with chronic diseases became particularly vulnerable and most at risk to nutrition imbalance. Firstly, available research indicated that adults 60 years and older and patients with preexisting medical conditions, especially heart disease, lung disease, diabetes or cancer are more likely to have severeeven deadly-coronavirus infection than other groups [23]. Second, the recommendations to stay home and abide by social distancing targeted these groups specifically, given their vulnerability. Third, the elderly and patients with chronic diseases may already be susceptible to malnutrition given their compromised health and limited purchasing ability. Therefore, at the level of the community, it is crucial to identify these vulnerable groups and extend assistance in food access and availability through a structured and reliable support system.

At the national level, while governments of countries around the globe are dealing with the burden of the COVID-19 and its enormous strains on the healthcare system, they are also battling a destabilization in their economies and a rising threat of food insecurity. In light of these challenges to provide adequate and nutritious food at times of pandemics, each country is urged to define, finance, and distribute a food basket of a least-cost diet that supports the health needs of the population, ensure the use of the local agricultural produce of the country, and minimize reliance on food imports. Significant planning is needed at the national level to increase the nation's preparedness, including the formulation of policies to support the production, distribution, and access of this food basket to different communities [24]. Among these policies are those related to mobilization of resources in order to finance food purchases and provisions, tax waiving for staple foods and commodities, and support for agricultural and food production industries. Given the effect of the COVID-19 pandemic on the demand and supply dynamics of food, price hikes became prevalent reaching at times uncontrollable levels, a situation that requires national efforts to closely monitor and inspect food prices and markets.

The COVID-19 pandemic imposed a paradigm shift on governments, whereby it became imperative to build networks with the private sector, the international agencies, and local communities. It is only through a coordinated effort of these different entities that securing essential nutritious food stocks become possible. Also, governments are asked to build and maintain open and two-way communication with the public during this pandemic, especially that transparency is critical for building trust, support, and compliance. Specific methods to inform the public about adequate food consumption and intake might include public awareness campaigns, nutrition education, emergency news bulletins, radio and TV announcements and interviews, and the dedication of specific telephone hotlines for direct communication with government representatives [25].

At the global level, while border protection is legitimate in safeguarding the health of citizens from external threats; however, it can severely disrupt travel, trade, and tourism, as well as infringe civil liberties [26]. Countries that depend heavily on imported food to meet demand might face inconsistent risk from supply chain failures, especially in the face of border crossing closures. Therefore, it is essential to ensure the smooth flow of global trade and make full use of the international markets as a vital tool to secure food supply across the globe to prevent food insecurity. An important lesson of the COVID-19 relates to its global nature whereby no country is immune to its spread and infliction: a global threat requires global action. The protectionist strategies that each country is implementing should be complemented by global cooperation, solidarity, and coordination among countries to ensure that humanity emerges from this pandemic with the least possible losses.

In conclusion, while much remains to be known about the COVID-19, the influence of this pandemic on nutrition and dietary intake has already gone beyond the individual and the community to reach national and global levels. A particular feature of this pandemic is highlighting the interdependence of these various levels, whereby the health of the individual became a direct function of his own awareness and choices, the unity of the community, the preparedness of the government, and ultimately the global engagement vis a vis this threat. In this perspective, a framework for action and recommendations is presented at each of those levels. A summary of these recommendations are presented in Fig. 2. The main goal of these recommendations is to maintain the physical and mental health of individuals, resilience of communities, and national and global food security. 
Fig. 2 Recommendations to mitigate the impact of COVID-19 on nutrition and food security.

Recommendations to mitigate the impact of COVID-19 on nutrition and food security at the individual, community, national and global levels.

\begin{tabular}{|c|c|}
\hline & Nutrition recommendations during COVID-19 pandemic \\
\hline 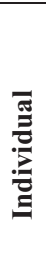 & $\begin{array}{l}\text { - Try to eat well-balanced meals, avoid irregular snacking } \\
\text { - Choose foods rich in vitamins A, C, E, B6 and B12, zinc, and iron such as } \\
\text { citrus fruits, dark green leafy vegetables, nuts, and dairy products. } \\
\text { - Maintain a healthy lifestyle of exercise (home-exercises), regular sleep and } \\
\text { - } \text { meditation } \\
\text { - } \\
\text { Refraid smoking, alcohol, and drugs } \\
\text { and the COVID-19 }\end{array}$ \\
\hline 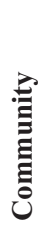 & $\begin{array}{l}\text { - Spread awareness regarding the devastating consequences of hoarding and } \\
\text { panic-buy } \\
\text { - Identify and support populations at risk of malnutrition within the community, } \\
\text { especially elderly and patients with chronic diseases } \\
\text { - Create a structured and reliable support system to ensure availability, access, } \\
\text { and affordability of essential food commodities to all members of the } \\
\text { community }\end{array}$ \\
\hline 胥 & $\begin{array}{l}\text { - Define, finance and distribute a food basket of a least-cost diet that addresses } \\
\text { the health needs of the population, ensures the use of the local agricultural } \\
\text { produce of the country, and minimizes reliance on food imports } \\
\text { - Mobilize resources in order to finance food purchases and provisions } \\
\text { - Waive taxation for staple foods and commodities } \\
\text { - Support agricultural and food production industries. } \\
\text { - Closely monitor and inspect food prices and markets. } \\
\text { - } \text { Build networks with the private sector, the international agencies, and local } \\
\text { communities } \\
\text { - Maintain high levels of transparency, critical to build trust, support, and } \\
\text { compliance }\end{array}$ \\
\hline $\begin{array}{l}\overline{\text { In }} \\
\text { 음 }\end{array}$ & $\begin{array}{l}\text { - Assure continuous flow of global trade, avoiding any trade restrictions would } \\
\text { be beneficial to keep food and feed supplies, as well as those of agricultural } \\
\text { inputs, from worsening local conditions already strained by COVID-19 } \\
\text { response measures } \\
\text { - Reduce import tariffs and other restrictions on food commodities }\end{array}$ \\
\hline
\end{tabular}

Author contributions FN led the conceptualization of this perspective. FN and RH wrote the draft. FN critically reviewed the final draft of the document.

\section{Compliance with ethical standards}

Conflict of interest The authors declare that they have no competing interests.

Publisher's note Springer Nature remains neutral with regard to jurisdictional claims in published maps and institutional affiliations.

\section{References}

1. Bogoch II, Watts A, Thomas-Bachli A, Huber C, Kraemer MU, Khan K. Pneumonia of unknown etiology in Wuhan, China: potential for international spread via commercial air travel. J Travel Med. 2020;272:1-3.

2. Zhu N, Zhang D, Wang W, Li X, Yang B, Song J, et al. A novel coronavirus from patients with pneumonia in China, 2019. N Engl J Med. 2020;382:727-33.

3. Gamage SD, Kravolic SM, Roselle G. Emerging infectious diseases: concepts in preparing for and responding to the next microbial threat. In: Koenig KL, Schultz $\mathrm{CH}$, eds. Koenig and Schultz's Disaster Medicine: Comprehensive Principles and Practices. Cambridge University Press; 2009:75-102.
4. Reissman DB, Watson PJ, Klomp RW, Tanielian TL, Prior SD. Pandemic influenza preparedness: adaptive responses to an evolving challenge. J Homel Sec Emerg Manag. 2006;3:1-24.

5. Cobb TD. Reclaiming our food: how the grassroots food movement is changing the way we eat. Storey Publishing, Adams, MA, USA; 2001.

6. Yousafzai AK, Rasheed MA, Bhutta ZA. Annual research review: improved nutrition-a pathway to resilience. J Child Psychol Psychiatry. 2013;54:367-77.

7. Hislop TG, Bajdik CD, Balneaves LG, Holmes A, Chan S, Wu E, et al. Physical and emotional health effects and social consequences after participation in a low-fat, high-carbohydrate dietary trial for more than 5 years. J Clin Oncol. 2006;24:2311-7.

8. Ma YJ, Lee HH. Understanding consumption behaviours for fair trade non-food products: focusing on self-transcendence and openness to change values. Int J Consum Stud. 2012;36:622-34.

9. Valdés-Ramos R, Martínez-Carrillo BE, Aranda-González II, Guadarrama AL, Pardo-Morales RV, Tlatempa P, et al. Diet, exercise and gut mucosal immunity. Proc Nutr Soc. 2010;69:644-50.

10. Wypych TP, Marsland BJ, Ubags ND. The impact of diet on immunity and respiratory diseases. Ann Am Thorac Soc. 2017;14: S339-47.

11. Gleeson M, Nieman DC, Pedersen BK. Exercise, nutrition and immune function. J Sports Sci. 2004;22:115-25.

12. Haug A, Brand-Miller JC, Christophersen OA, McArthur J, Fayet F, Truswell S. A food "lifeboat": food and nutrition considerations in the event of a pandemic or other catastrophe. Med J Aust. 2007; 187:674. 
13. Duerr HP, Brockmann SO, Piechotowski I, Schwehm M, Eichner M. Influenza pandemic intervention planning using InfluSim: pharmaceutical and non-pharmaceutical interventions. BMC Infect Dis. 2007;7:76.

14. Hobbs M, Pearson N, Foster PJ, Biddle SJ. Sedentary behaviour and diet across the lifespan: an updated systematic review. Br J Sports Med. 2015;49:1179-88.

15. Scully M, Dixon H, Wakefield M. Association between commercial television exposure and fast-food consumption among adults. Public Health Nutr. 2009;12:105-10.

16. Anton SD, Miller PM. Do negative emotions predict alcohol consumption, saturated fat intake, and physical activity in older adults? Behav Modif 2005;29:677-88.

17. Macht M. Characteristics of eating in anger, fear, sadness and joy. Appetite 1999;33:129-39.

18. Macht M. How emotions affect eating: a five-way model. Appetite 2008;50:1-11.

19. Vallianatos M, Azuma AM, Gilliland S, Gottlieb R. Peer reviewed: food access, availability, and affordability in 3 Los Angeles communities, project CAFE, 2004-2006. Prev Chronic Dis. 2010;7:1-9.
20. Vo TLH, Thiel D. A system dynamics model of the chicken meat supply chain faced with bird flu. University of Nantes: Nantes, France; 2006.

21. Kohn S, Eaton JL, Feroz S, Bainbridge AA, Hoolachan J, Barnett DJ. Personal disaster preparedness: an integrative review of the literature. Disaster Med Public Health Preparedness. 2012;6:217-31.

22. Timmer CP. Reflections on food crises past. Food Policy 2010;35:1-11.

23. World Health Organization. Coronavirus disease 2019 (COVID-19): situation report, 51. World Health Organization, Geneva; 2020.

24. Homeland Security Council. National strategy for pandemic influenza: implementation plan. Homeland Security Council, Washington (D.C.); 2006.

25. Pan American Health Organization. Tool 11: distribution of emergency food during a pandemic. https://www.paho.org/disa sters/index.php?option $=$ com_docman $\& v i e w=$ download $\&$ ca tegory_slug=tools\&alias $=538$-pandinflu-leadershipduring-tool$11 \&$ Itemid $=1179 \&$ lang $=$ en.

26. Gostin L. Public health strategies for pandemic influenza: ethics and the law. Jama 2006;295:1700-4. 